\title{
Development of a Control System for an Autonomous Underwater Vehicle
}

\author{
I.Masmitja, G. Masmitja, J. González, S. Shariat-Panahi, S. Gomariz, \\ SARTI Research Group. Department of Electronic Engineering. Technical University of Catalonia. \\ Avda. Victor Balaguer s/n. 08800 Vilanova i la Geltrú. Barcelona. Spain.
}

\begin{abstract}
This work proposes the development of a control system for an autonomous underwater vehicle dedicated to the observation of the oceans. The vehicle, a hybrid between Autonomous Underwater Vehicles (AUVs) and Autonomous Surface Vehicles (ASV), moves on the surface of the sea and makes vertical immersions to obtain profiles of a water column, according to a pre-established plan. The displacement of the vehicle on the surface allows the navigation through GPS and telemetry communication by radio-modem. The vehicle is $2300 \mathrm{~mm}$ long by $320 \mathrm{~mm}$ wide. It weighs $85 \mathrm{~kg}$ and reaches a maximum depth of $30 \mathrm{~m}$. A control system based on an embedded computer is designed and developed for this vehicle that allows a vehicle's autonomous navigation. This control system has been divided into navigation, propulsion, safety and data acquisition subsystems.
\end{abstract}

\section{INTRODUCTION}

Traditionally, oceanographic vessels have been and are the most important observation platforms where multidisciplinary oceanographic studies are carried out. The high cost of using them prevents to get data with spatial and temporal resolution required. A recent alternative way, which allows ocean observations with good spatial and temporal resolution simultaneously and with lower costs are the Gliders, the Autonomous Underwater Vehicles (AUVs) and Autonomous Surface Vehicles (ASVs) [1] [2].

There is a type of hybrid vehicle in underwater observation that lies between the AUVs and ASVs, ie moving along the surface of the sea and makes vertical immersions to obtain profiles of water column. [3] [4].

The vehicle control system developed belongs to the latter group [5] [6]. It has a double hull structure where the outer hull, made of fiberglass, provides a good vehicle hydrodynamic behaviour (see figure 1a), but not watertight. On this heading and propulsion engines are coupled. On the tail and the longitudinal axis of the vehicle the main Seaeye (300W) propulsion engine is located and on the sides two separate Seabotix (80W) engines, see figure $1 \mathrm{~b}$. Inside the outer case a cylindrical waterproof aluminium 6063 module is attached that contains the immersion and emersion actuator, the battery pack and control system (see Figure 2). The immersion actuator is a commercial pneumatic stainless steel cylinder with a displacement of $1500 \mathrm{~cm}^{3}$ and a linear electric actuator which can cover a maximum distance of $200 \mathrm{~mm}$ and thrust force of $3 \mathrm{KN}$. Power batteries are Ni-Cd providing $21 \mathrm{Ah}$, and $24 \mathrm{~V}$ voltage [7]. In order to supply $5 \mathrm{~V}$ and $12 \mathrm{~V}$ voltages required for different electronic devices Mornsun dcdc switching converters have been used.

This work is organized as follows: section II shows the control system structure and design of communication subsystems, navigation, propulsion and safety. Section III presents the experimental results obtained in the laboratory. Section IV creates a graphical interface that allows monitoring of the control system parameters. Finally, Section V presents the conclusions.

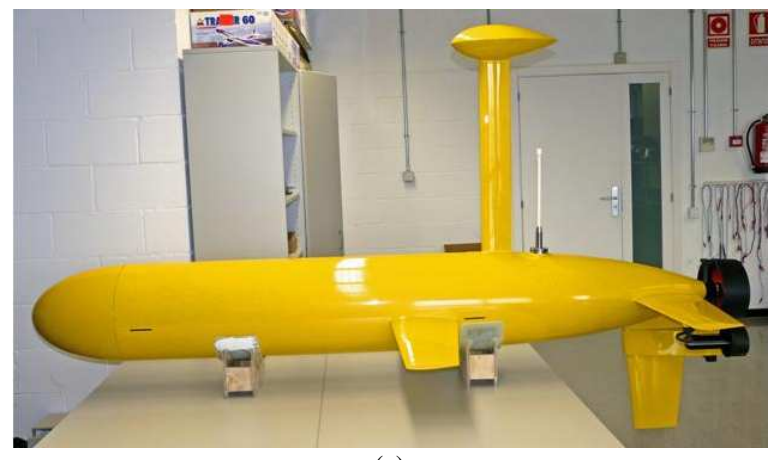

(a)

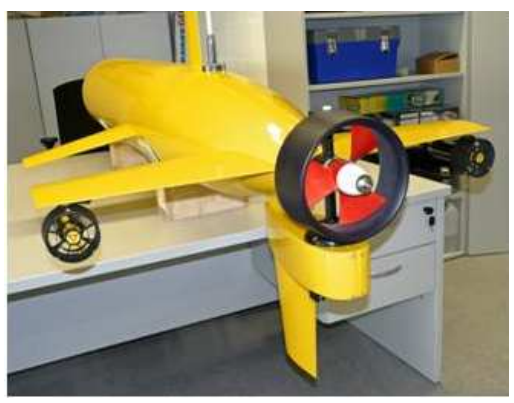

(b)

Figure 1. Autonomous Underwater Vehicle used. (a) Side view (b) Tail view.

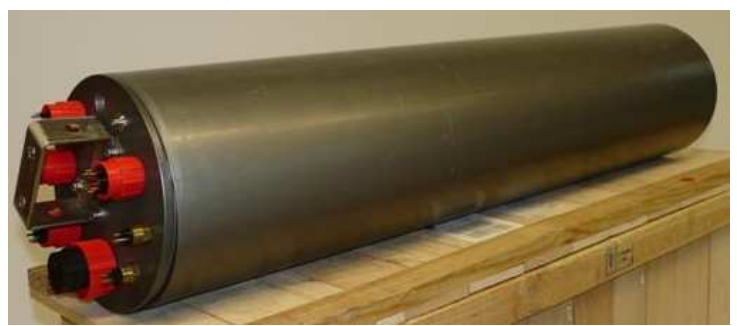

Figure 2. Interior Watertight Module. 


\section{CONTROL SYSTEM DESIGN}

The control system is designed in a modular way with different subsystems, managed by the module control unit, which consists of a PC104 embedded computer. Figure 3 shows a block diagram of the control system. As seen, there are six modules: the control unit, the navigation system, the propulsion/immersion system, safety system, communication system and data acquisition system. The following describes each of these systems, except the data acquisition system that will be configured according to the objectives of the mission.

\section{A. Control Unit}

The vehicle is controlled by an embedded computer with Aewin PC104+ assembly [8], model PM_6100. It works with a CPU AMD ${ }^{\circledR}$ Geode ${ }^{T M}$ LX800, 500MHz. It has low energy consumption $(\max .12 \mathrm{~W})$ with a right size. It operates with Windows XP operating system and the data storage system is a compact flash that provides good protection against vibration. Programming is performed through the graphical programming tool NI_LabVIEW. Figure 4 shows a block diagram of devices and systems connected to PC104. The control unit is equipped with an MSMX104+ expansion card with RS232/RS485 ports, providing up to 8 ports to control various devices. It has also been equipped with a PC104-DAS16JR/12 data acquisition card with 16 analog inputs and a resolution of 12 bits, $150 \mathrm{kBps}$ and 8 digital inputs, to obtain data from analog and digital sensors.

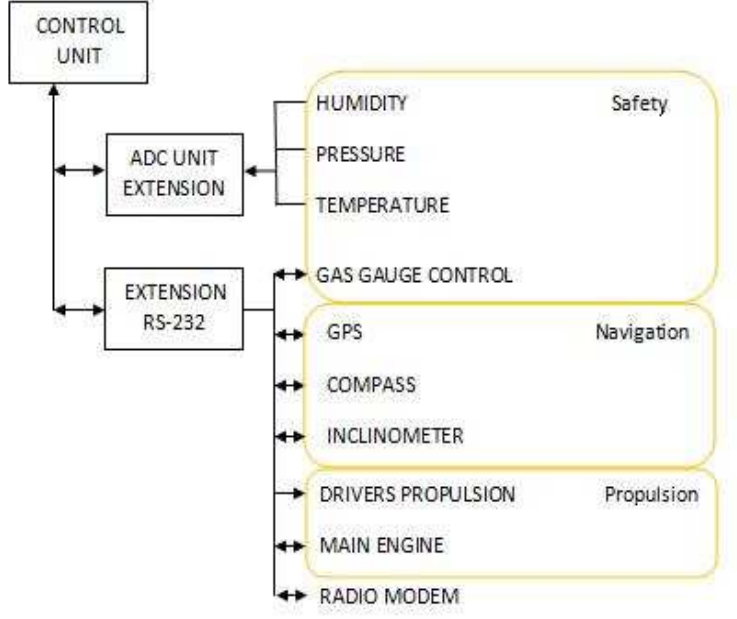

Figure 4. Block diagram of the devices connected to the PC104

B. Navigation System

In order to know the position of the vehicle, it has been equipped with a GPS navigation system. The receiver is the Magallen DG14 ${ }^{\mathrm{TM}}$ [9], which offers high accuracy by incorporating signal Satellite Based Augmentation Systems (SBAS), allowing an optimal real-time navigation controlled through a standard RS232 port. To acquire the signals from the satellites, there is a $50 \Omega$ passive AT575_75 antenna, with $35 \mathrm{~dB}$ power and a noise figure of $2.4 \mathrm{~dB}$.

Also, the navigation system features a digital compass and a 3 -axis altitude indicator integrated in the TCM-2.6 [10]. The TCM-2.6 is a 3-axis compass with tilt compensation (known as pitch, yaw and roll) with a tilt range of $\pm 80^{\circ}$. The navigation system offers high accuracy (precision $0,8^{\circ}$ ) resolution (compass $0,1^{\circ}$ ) and a low power consumption $(<20 \mathrm{~mA}$ typical).

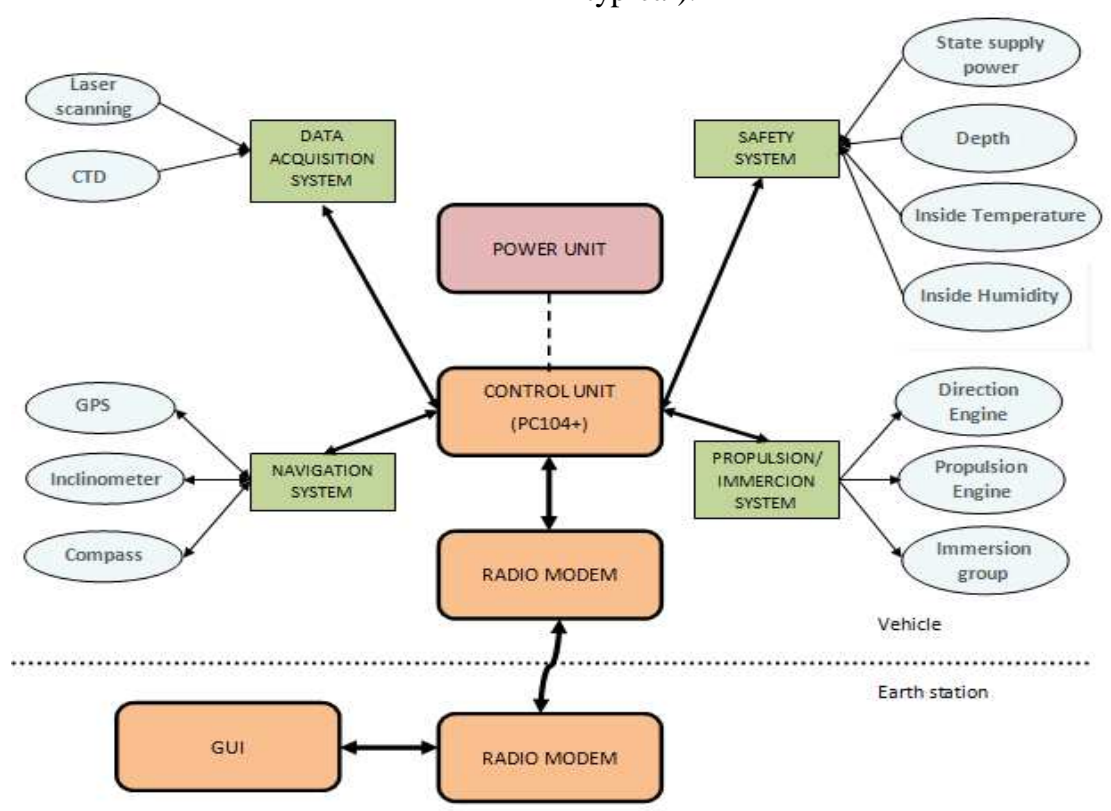

Figure 3. Block diagram of the structure of the control system designed. 


\section{Propulsion Immersion System}

As it can be seen in Figure 5, the propulsion/immersion system comprises: a main engine, which provides the propulsion, two side engines, which monitor the direction of the vehicle and a pneumatic stainless cylinder allows to dive.

The main engine, the Seaeye SI-MCT01-B [11] provides a nominal power of $300 \mathrm{~W}$ to $960 \mathrm{rpm}$ together with the drivers, integrated control and power.

The side engines are BTD150 Seabotix [12] engines, providing a maximum thrust of $25 \mathrm{~N}$ to a maximum power of $80 \mathrm{~W}$. For these engines a specific driver was designed for control and power.

Finally, the immersion/emersion system is a Festo CRDNG100-PPV-A pneumatic stainless cylinder [13], controlled by a driver designed specifically for this task.

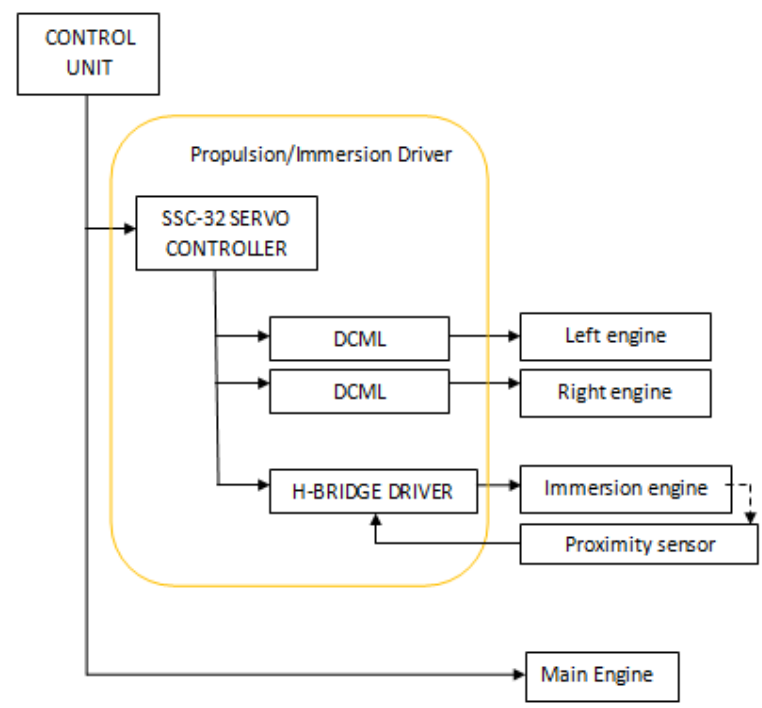

Figure 5. Block diagram of the immersion/emersion system of the vehicle.

As Figure 5 shows, the PC104 controls the main engine directly through a serial communication RS485 protocol, while, other engines are controlled by the SSC-32 device, which uses a RS232 communication.

The SSC-32 of Lynxmotion [14] is a driver that allows to control up to 32 outputs via an RS232 serial communication. These outputs provide a signal with a variable pulse width determined by the user of $500 \mu$ s to $2500 \mu \mathrm{s}$, with a specific frequency. The designed driver (DCML) can transform these variables into a Pulse Width Modulation (PWM) signal, suitable for motor control.

Figure 6 shows the block diagram of the DCML control driver designed. First, it filters the signal coming from the SSC-32, thus a reference voltage is obtained, which is compared with a triangular signal, previously generated, producing the PWM signal. Finally the amplifier is responsible for transferring power to the motor.

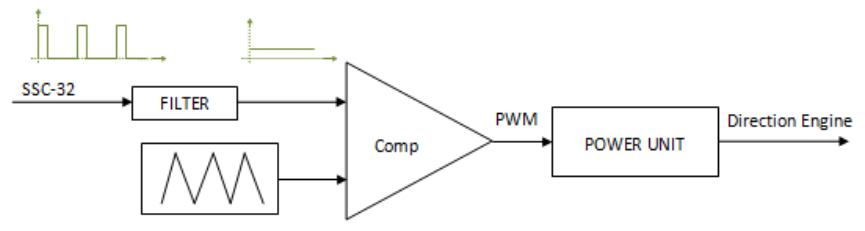

Figure 6. Block diagram of the control driver for side engines

For the side engines, an amplifier is designed using a power MOSFET transistor providing $0 \mathrm{~V}$ or $24 \mathrm{~V}$ to the engines. While for the control piston engine, a $\mathrm{H}$-bridge is implemented to provide bi-directionality to the piston, needed to perform diving operations and emersion. In addition, it includes progressive on and off ramps to avoid over-currents and voltage drops.

Remarkably, the immersion group has two SMEO proximity sensors at the end, to control the piston stroke.

\section{Safety System}

The vehicle has been equipped with safety systems that allow monitoring system variables that can become critical to the overall operation. These are:

State of battery charge: is monitored through a RS232 port, indicating the remaining power in batteries by means of a Texas Instruments charge status indicator. This device uses Coloumb Counting control system, to sense the incoming and outgoing energy from the batteries. Figure 7 shows the system connection charge state with the energy system of the vehicle.

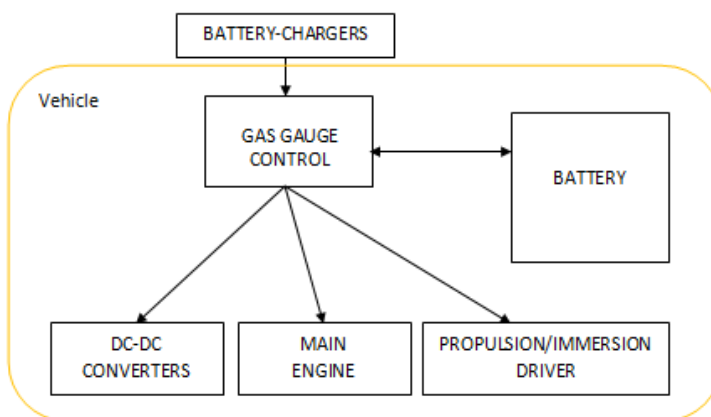

Figure 7. Block diagram of the state of battery charge

Depth: a watertight module of a pressure sensor, GEMS 2200 series with a range of 0-6 bar and a sensitivity of 0.833 ( $\mathrm{V} /$ bar), has been placed outside the vehicle. This allows us to monitor the depth of the dive between $0 \mathrm{~m}$ to $60 \mathrm{~m}$.

Humidity/Temperature: a humidity and temperature sensor has been placed inside the watertight module to check the level of sealing and to ensure the proper functioning of electronic systems.

\section{E. Radio Modem System}

The vehicle is connected to the base station via a radio link, which allows receiving real-time data and vehicle parameter 
monitoring, making it easier to control. The radio link is a TMOD-C48 Farrell radio modem, [15]

The TMOD-C48 works in the frequency range of $403 \mathrm{MHz}-$ $470 \mathrm{MHz}$ (UHF). It has a bidirectional connection with a transmission speed of $4800 \mathrm{bps}$ and stability of $\pm 1 \mathrm{ppm}$ from $30^{\circ} \mathrm{C}$ to $60^{\circ} \mathrm{C}$. The transmission power is $0.1 \mathrm{~W}$ to $5 \mathrm{~W}$, allowing a maximum range of $10 \mathrm{~km}$.

\section{EXPERIMENTAL RESULT}

All electronic control system of the vehicle is located inside four PVC boxes, as shown in Figure 8. The control unit, located in the first place, has forced ventilation and external connections for the control of the CPU (monitor, mouse, keyboard and USB). Below is a box with regulators switched $12 \mathrm{~V}$ to $5 \mathrm{~V}$ supply. In another box the motor control drivers and the SSC-32 controller were grouped. Finally, the box with the GPS navigation and compass/altitude, the radio modem and the humidity sensor. All PVC boxes were distributed on an aluminium support which enables convenient handling and installation.

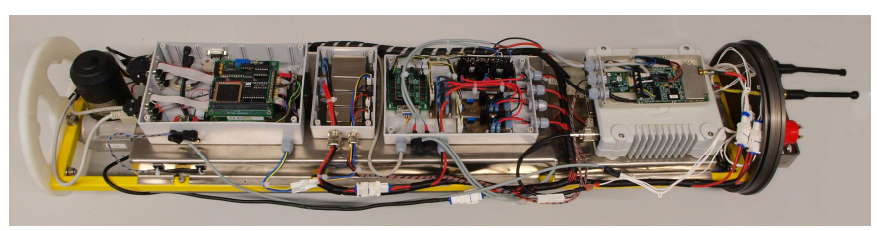

Figure 8. Location of the electronic control system

All electronic control system designed has been tested and verified by laboratory tests and field trials.

To verify the correct operation of the propulsion-system, graphs of the voltage and current of different motors have been obtained. Figure 9 shows the voltage and current of the main engine, in steady and in the start situation, $50 \%$ of its power. To avoid the current peak seen in these conditions to start the engine, a software soft-start is implemented, not allowing power increase above $10 \%$. Figure 10 represents the voltage and current in the side motor. Regarding the piston engine, Figure 11 compares the improvement in the fall of the supply voltage to perform a soft-start of piston engine, with a direct start. It is possible to decrease the voltage to $70 \%$.

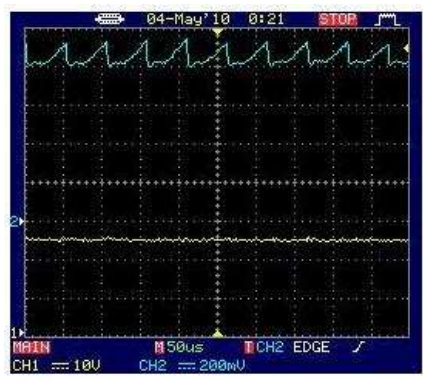

(a)

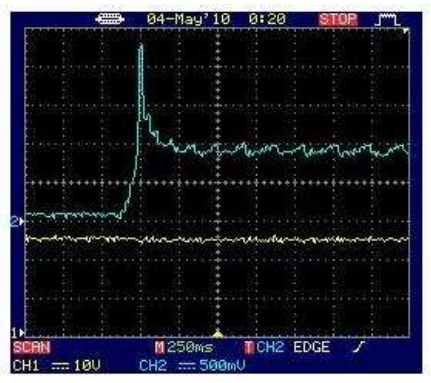

(b)
Figure 9. Voltage and current in the main motor (a) steady state, (b) start.

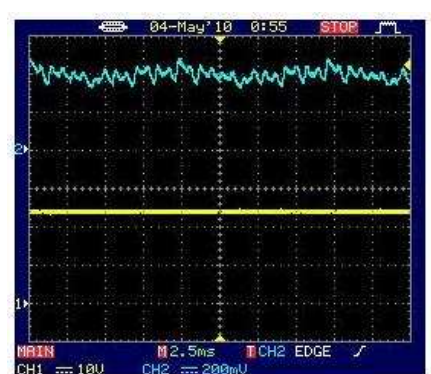

(a)

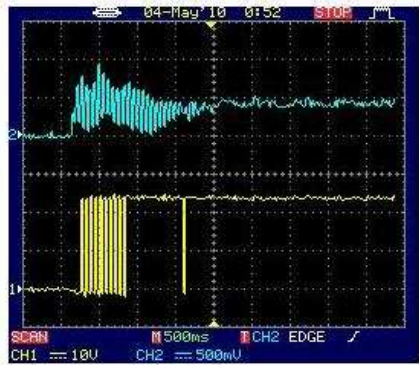

(b)
Figure 10. Voltage and current in the side motor (a) steady state, (b) start.

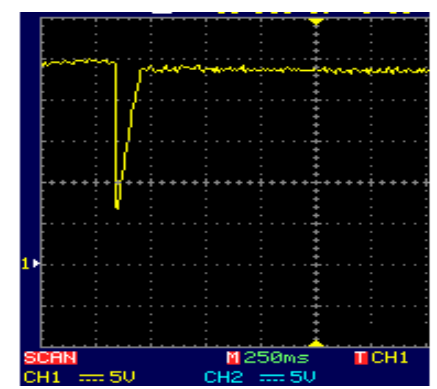

(a)

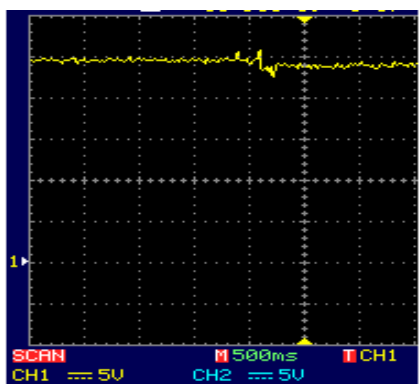

(b)
Figure 11. Power supply to the piston-boot (a) direct, (b) progressive start.

The proper functioning of the navigation system and radio modem is verified in Figure 12, which notes the altitude of the vehicle. These graphics have been created from data received in the base station field trials.

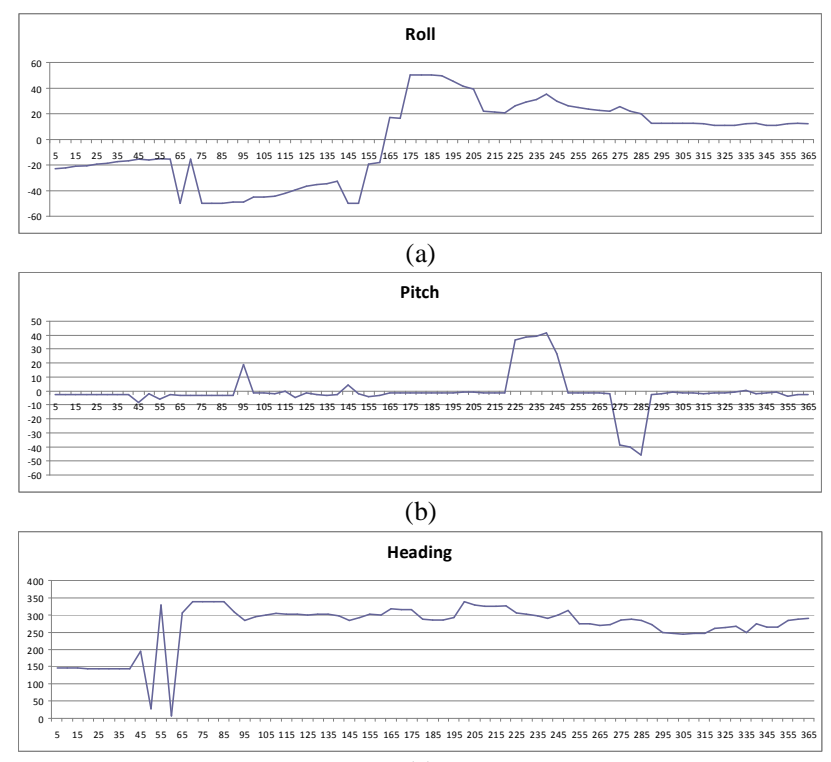

(c)

Figure 12. Vehicle altitude (a) Roll (b) Pitch (c) Heading 


\section{GRAPHICAL USER INTERFACE (GUI)}

The vehicle needs user interaction in terms of parameter control, operational verification, data acquisition and downloading. A program has been designed which reads/writes the data received/sent by radio-modem, checks for transmission errors and represents the information graphically. The graphical user interface (GUI) has a four-page front-end. Figure 13 shows the main page. This incorporates indicators of the heading, speed, vehicle altitude and engine power. This page also includes a series of Scrollbars and buttons to manual control the vehicle engines.

The second page shows the values from all sensors incorporated into the vehicle. There are indicators for the altitude of the vehicle, the energy status of each battery pack, humidity, temperature, pressure, depth and GPS position. The third page shows the time graphs of different variables of the sensors.

The fourth page presents the user with each of the parameters that the GPS receiver provides using TextBox and a variety of geo-maps (Google) to locate the position of the vehicle.

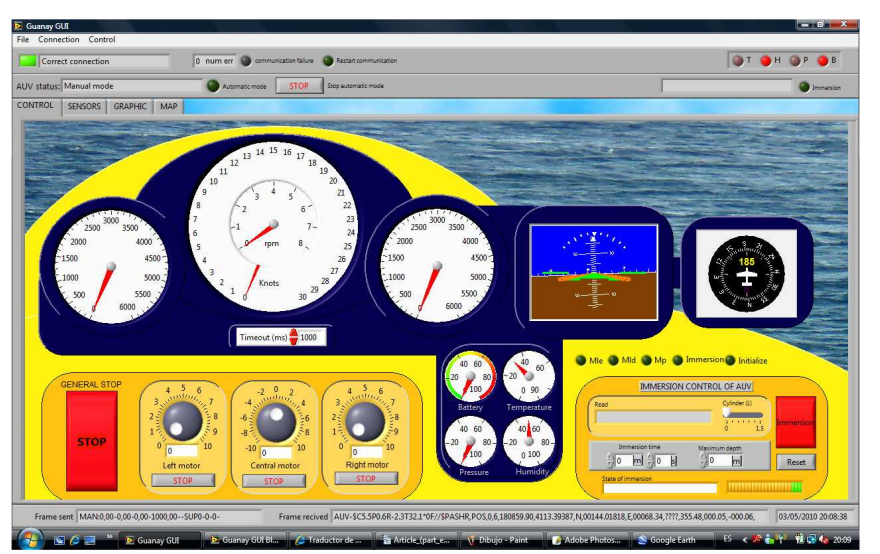

Figure 13. Tracking Station. GUI Main Page

\section{CONCLUSIONS}

This work provides a control system for an autonomous underwater vehicle. The developed platform is robust, relatively small and lightweight, factors which facilitate its manageability and operability. It incorporates an embedded computer that manages the navigation, propulsion and safety systems of the vehicle. Given their high performance, the incorporation of trajectory control algorithms is feasible. Also, specific hardware and software designed for the correct operation of the sensors and thrusters.

Laboratory and field testing have shown their proper operation.

\section{ACKNOWLEDGMENT}

This work has been funded by the Spanish Ministry of Education and Science and the European Union (FEDER), project $n^{\circ}$ : CTM2006-12072/MAR.

\section{REFERENCES}

[1] Meyrowitz, A.L.; Blidberg, D.R. and Michelson, R.C. "Autonomous vehicles". Proceedings of the IEEE. Volume 84, Issue 8, pp 1147 - 1164. 1996

[2] Blidberg, D. R. "The development of Autonomous Underwater Vehicles (AUV); A brief summary. Autonomous Undersea Systems Institute publications (AUSI), ICRA, May,200.1 Seoul, Korea,.

[3] Dabholkar, N., Desa, E., Afzulpurkar, S., Madhan, R., Mascarenhas, A.A.M.Q., Navelkar, G., Maurya, P.K., Prabhudesai, S., Nagvekar, S., Martins, H., Sawkar, G., Fernandes, P. and Manoj, K.K. "Development of an autonomous vertical profiler for oceanographic studies" Proceedings of the International Symposium on Ocean Electronics (SYMPOL-2007), 11-14 December, 2007.Cochin, India, pp. 250-256.

[4] Byron, J. and Tyce, R. "Designing a Vertical / Horizontal AUV for Deep Ocean Sampling". Proceedings of MTS/IEEE Conference and Exhibition Oceans 2007. Sept. 29 2007-Oct. 4. Vancouver, Canada pp. 1 - 10.

[5] Gomáriz S, Prat, J., Sole J., Gayà P. "An autonomous vehicle development for submarine observation." Journal of Marine Research. VI-2. pp 23-35 August 2009.

[6] Gomáriz, S. Prat, J. Arbos, Viñolo, C. Pallares, O. “Autonomous Vehicle development for vertical submarine observation". International Workshop on Marine Technology. Vilanova i la Geltrú. November 2009.

[7] Gomáriz S, Prat, J., Sole J., Gayà P. "Development of low-cost autonomous oceanographic observation vehicle”. Oceans'09 MTS/IEEE. May 2009.Bremen. Germany

[8] Aeewin

http://www.aewin.com.tw/main/product_info.aspx?fid=2\&sid=3\&sname $=$ Embedded + Board $\&$ pname $=$ PM$6100 \&$ tname $=$ PC $\% 2 F 104+C P U+$ Module $\&$ fname $=\& p i d=27$.

[9] Magellan, http://pro.magellangps.com/en/products/product.asp?PRODID=174.

[10] PNI, http://www.pnicorp.com/products/all/tcm-2-6

[11] Seaeye, http://seaeye.com/thrusters.html.

[12] Seabotix, http://seabotix.com.

[13] Festo

[14] Lynxmotion, http://www.lynxmotion.com/Product.aspx?productID=395\&CategoryID= 52.

[15] Farell, http://www.farell-i.com/farell/eng/productos.php. 